\title{
SEROPREVALENCE OF HEPATITIS B AND HEPATITIS C INFECTIONS IN PATIENTS WITH LIVER DISEASES
}

\author{
Hyma Pratyusha Yakasiri ${ }^{1}$, Suguneswari ${ }^{2}$
}

${ }^{1}$ Assistant Professor, Department of Microbiology, Viswabharathi Medical College, Kurnool. ${ }^{2}$ Associate Professor, Department of Microbiology, Viswabharathi Medical College, Kurnool.

ABSTRACT
BACKGROUND
Hepatitis B and hepatitis C viruses are endemic in India. These are the most important aetiological agents for the development of
chronic liver diseases and hepatocellular carcinomas. The prevalence of these infections varies from place to place and among
different age groups and also based on the vaccination coverage for hepatitis B.

\section{MATERIALS AND METHODS}

In the present study, 200 serum samples were tested for hepatitis B surface antigen and hepatitis C antibody by performing ELISA. 100 samples were from the patients suffering from liver diseases, which are the study group and 100 from healthy population attending General OP and Gastroenterology OP which acts as control group.

\section{RESULTS}

In the study group, out of 100 patients hepatitis B infection alone was observed in $36 \%$ of the patients and hepatitis $\mathrm{C}$ alone in $24 \%$ of the patients. Dual infection with both the viruses was seen in $8 \%$ of the patients. In the healthy group, the prevalence of hepatitis $\mathrm{B}$ and $\mathrm{C}$ were $10 \%$ and $3 \%$ respectively and no co-infection was noted in the control group.

\section{CONCLUSION}

Hepatitis B and Hepatitis C virus infections are more common cause of liver diseases. Coinfection with both the viruses is becoming more common and is associated with more severe disease manifestations when compared to the either of the infection alone.

\section{KEYWORDS}

Hepatitis B Virus, Hepatitis C Virus, Coinfection.

HOW TO CITE THIS ARTICLE: Yakasiri HP, Suguneswari. Seroprevalence of hepatitis B and hepatitis C infections in patients with liver diseases. J. Evolution Med. Dent. Sci. 2016;5(99):7241-7243, DOI: 10.14260/Jemds/2016/1638

\section{BACKGROUND}

Viral hepatitis is one of the major health problems worldwide. It is caused by a wide range of hepatotropic viruses among which hepatitis $\mathrm{B}$ and $\mathrm{C}$ are the most important ones which have gained much of importance because of their mode of transmission, carrier state and consequences like cirrhosis and hepatocellular carcinoma. These two viruses are endemic in India contributing to significant mortality and morbidity. Hepatitis B is responsible for approximately 300 million cases of chronic liver infection worldwide with an account of around 43 million carriers in India. ${ }^{1}$ The prevalence of hepatitis $\mathrm{C}$ infection in India varies between 0.3 to $11.3 \%$ and is now the major cause of transfusion associated hepatitis. ${ }^{2}$

These two viruses pose a great burden on the health care system worldwide, both in terms of loss of manpower as well as economic burden requiring high cost management. Early detection of these infections may not only prevent further damage but also improve the outcome in patients. The present study was conducted to know the prevalence of both hepatitis $B$ and $C$ infections in patients presenting with liver diseases to our Hospital.

Financial or Other, Competing Interest: None.

Submission 15-04-2015, Peer Review 28-11-2016,

Acceptance 05-12-2016, Published 12-12-2016.

Corresponding Author:

Dr. Hyma Pratyusha Yakasiri

H.No:78/126-A, First Line,

Krishna Nagar, Kurnool-518002,

Andhra Pradesh, India.

E-mail: drhymapratyusha@gmail.com

DOI: $10.14260 /$ jemds $/ 2016 / 1638$

\begin{abstract}
Aims and Objectives
The study was done for a period of 2 years (2005 - 2007) to know the prevalence of hepatitis $\mathrm{B}$ and $\mathrm{C}$ in liver disorder patients attending the Government General Hospital, Kurnool.
\end{abstract}

\section{MATERIALS AND METHODS}

The study included 200 serum samples, 100 of which were collected from the patients suffering from the liver diseases attending the Gastroenterology Department. The study group included new cases and already known followup cases. 100 samples of control group were collected from apparently healthy individuals, who did not have any history of liver diseases previously. Control group samples were collected from individuals attending both general $O P$ and Gastroenterology OP. All were initially screened for HBsAg with immunochromatographic rapid card test. After screening for HBsAg, then all the samples were tested for hepatitis $B$ surface antigen and antibodies to hepatitis $C$ by using Bio-Tech HBsAg Elisa and HCV Elisa.

\section{Bio-Tech HBsAg Elisa}

Hepascan HBsAg Elisa is a non-competitive sandwich Elisa, in which monoclonal anti-HBsAg antibody coated on the microtitre well act as capture antibody. Serum was added to the microtitre wells. If the test sample contains Hepatitis B surface antigen, it binds to the anti-HBsAg antibody. After washing the unbound components, the bound antigen was detected by horseradish peroxidase conjugated to goat antiHBsAg. After further washing followed by incubation with substrate containing chromogen produces a coloured 
complex, the intensity of which was measured by Elisa reader as absorbance value. Positive and negative samples are detected based on the cut-off value.

\section{Bio-Tech HCV Elisa}

Test sample was added to the microtitre well plates coated with HCV antigens. If the samples contain antibodies, it binds to the coated antigen. After washing the unbound antibodies, protein A horseradish peroxidase conjugate was added which binds to the antibody to form antigen antibody conjugate complex. Unbound conjugate was removed by subsequent washing. Tetramethylbenzidine substrate was added and incubated. In the presence of antigen antibody complex, the colourless TMB substrate was hydrolysed to form a blue end product. Absorbance was read by Elisa reader and based on cut-off values positive and negative samples were detected.

Bio-Tech Elisa for HBsAg and HCV is $96.2 \%$ sensitive and $99.3 \%$ specific.

\section{RESULTS}

A total of 200 samples (100 study group +100 control group) were screened for hepatitis B surface antigen and anti-HCV antibodies simultaneously.

In the study group, 62 were males and 38 were females. In the control group, 60 were males and 40 were females.

\begin{tabular}{|c|c|c|c|}
\hline & Male & Female & Total \\
\hline Study Group & 62 & 38 & 100 \\
\hline Control Group & 60 & 40 & 100 \\
\hline
\end{tabular}

In the study group, out of 100 patients $36(36 \%)$ were positive for hepatitis B surface antigen and 24 (24\%) were positive for hepatitis $C$ antibody and 8 (8\%) patients were positive for both and are thus considered as coinfection cases. Thus, a total of 68 patients were positive for one or other hepatitis. In the control group, out of 100 patients $10(10 \%)$ were positive for hepatitis B surface antigen and 3 (3\%) were positive for hepatitis $\mathrm{C}$ antibody. No coinfection cases were found. In total, the prevalence of positivity was $13 \%$ in the control group.

\section{Seroprevalence of Hepatitis Cases}

\begin{tabular}{|c|c|c|c|c|c|c|}
\hline & 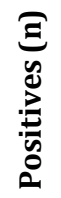 & 鲁 & 己 & ن̃ & 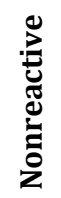 & $\begin{array}{l}\text { J゙ } \\
\stackrel{0}{0}\end{array}$ \\
\hline Study Group & 68 & $36 \%$ & $24 \%$ & $8 \%$ & 32 & 100 \\
\hline Control Group & 13 & $10 \%$ & $3 \%$ & - & 87 & 100 \\
\hline
\end{tabular}

Seroprevalence of HBV, HCV and Coinfection in Different age Groups

\begin{tabular}{|c|c|c|c|}
\hline Age Groups & HBV Positive & HCV Positive & Coinfection \\
\hline $10-20$ & $3(8.33 \%)$ & $2(5.5 \%)$ & - \\
\hline $21-30$ & $12(33.3 \%)$ & $10(41.6 \%)$ & $4(50 \%)$ \\
\hline $31-40$ & $12(33.3 \%)$ & $8(33.3 \%)$ & $2(25 \%)$ \\
\hline $41-50$ & $6(16.6 \%)$ & $3(12.5 \%)$ & $2(25 \%)$ \\
\hline
\end{tabular}

\begin{tabular}{|c|c|c|c|}
\hline $51-60$ & $2(5.5 \%)$ & $1(4.1 \%)$ & - \\
\hline $61-70$ & $1(2.78 \%)$ & - & - \\
\hline Total & $\mathbf{3 6}$ & $\mathbf{2 4}(\mathbf{2 4 \% )}$ & $\mathbf{8 ( 8 \% )}$ \\
\hline
\end{tabular}

The prevalence of hepatitis B was highest in the age group of $21-30$ and 31 - 40, together constituting $66.6 \%$ of the total positives. Hepatitis C prevalence was highest in the $21-30$ years' age group accounting for $41.6 \%$ of the total positives. Coinfection with both the viruses was also commonly seen in the 21 - 30 years' age group with $50 \%$ of the cases identified as having coinfection with both hepatitis $B$ and $C$.

The least prevalence of any of these viruses is seen in the age group of $61-70$ years with only $2.78 \%$ of the hepatitis $B$ positive and no hepatitis $\mathrm{C}$ positive cases.

\section{Prevalence of HBV, HCV and Coinfection in Risk Categories}

\begin{tabular}{|c|c|c|c|c|}
\hline 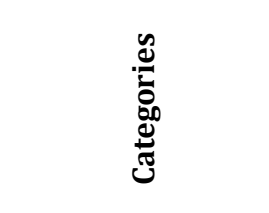 & 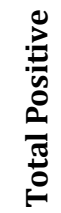 & 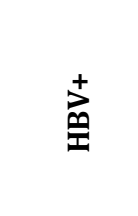 & $\stackrel{+}{\stackrel{+}{2}}$ & ن̃ \\
\hline $\begin{array}{l}\text { Multiple sex } \\
\text { partners }\end{array}$ & 12 & $\begin{array}{c}7 \\
(58.3 \%)\end{array}$ & $\begin{array}{c}3 \\
(25 \%) \\
\end{array}$ & $2(16.6 \%)$ \\
\hline $\begin{array}{l}\text { Recipients of blood } \\
\text { transfusion }\end{array}$ & 3 & $\begin{array}{c}1 \\
(33.3 \%) \\
\end{array}$ & $\begin{array}{c}1 \\
(33.3 \%) \\
\end{array}$ & $\begin{array}{c}1 \\
(33.3 \%) \\
\end{array}$ \\
\hline Drug abusers & 1 & - & - & $\begin{array}{c}1 \\
(100 \%)\end{array}$ \\
\hline $\begin{array}{c}\text { Sporadic } \\
\text { transmission }\end{array}$ & 52 & $\begin{array}{c}28 \\
(53.8 \%)\end{array}$ & $\begin{array}{c}20 \\
(38.4 \%)\end{array}$ & $\begin{array}{c}4 \\
(7.6 \%)\end{array}$ \\
\hline Total & 68 & $\begin{array}{c}36 \\
(52.9 \%)\end{array}$ & $\begin{array}{c}24 \\
(35.2 \%)\end{array}$ & $\begin{array}{c}8 \\
(11.7 \%)\end{array}$ \\
\hline
\end{tabular}

With regards to the risk factors for acquiring hepatitis in the study group, 12 out of 100 patients had multiple sex partners and 3 were recipients of blood transfusion and 1 was a drug abuser. The remaining 52 patients were not having any notable risk factors and are considered as cases of sporadic transmission (cryptogenic cases).

Out of 12 patients who had a risk factor of multiple sex partners, the prevalence of hepatitis B infection alone is higher (58.3\%) followed by hepatitis C (25\%). The coinfection was also observed in $16.6 \%$ of the positive cases.

In the patients who had received blood transfusion both hepatitis B and C accounted equally (33.3\% each) with the coinfection rate of $33.3 \%$. Only coinfection with both the viruses was noted in the single patient who had a history of drug abuse.

\section{DISCUSSION}

End stage liver disease is one of the leading causes of death in hospitals. Infection by hepatitis viruses continues to be the major cause of chronic liver disease. Hepatitis B and C viruses account for a substantial proportion of the diseases worldwide. Hepatitis $\mathrm{B}$ and $\mathrm{C}$ viruses have an aetiological role in acute hepatitis, $50 \%$ to $70 \%$ of which lead to chronic hepatitis and other complications.

Hepatitis B and C viruses share same modes of transmission, so coinfection with the two viruses is not uncommon. Coinfection is a frequent occurrence, particularly 
in areas where the two viruses are endemic. Patients with dual infection have more severe liver disease and are at an increased risk of progression to hepatocellular carcinoma. Dual infection is refractory to therapy when compared to infection with individual viral agents.[3] In the present study out of the 100 samples collected from patients with liver disorders, 36 samples (36\%) were positive for hepatitis B, $24 \%$ for Hepatitis C and $8 \%$ for dual infection. The prevalence of $36 \%$ hepatitis B infection in the present study correlates with Singh et $\mathrm{al}^{4}$ study who reported a prevalence of $30 \%$ in patients of chronic liver disease. The prevalence of hepatitis $\mathrm{C}$ in the same study was $48 \%$, whereas in our study it was only $24 \%$. The $8 \%$ coinfection rate correlates well with the Singh et al study, where $6 \%$ were having coinfection.

In another study conducted by Chakravarti et al 5 from New Delhi, $60.6 \%$ of the patients with chronic liver disease were suffering from hepatitis B and $25.75 \%$ with hepatitis C. The coinfection was considerably high in their study when compared to our study with $20.45 \%$ of the patients having dual infection. In Vandana et $\mathrm{al}^{2}$ study only $1.90 \%$ of the patients with hepatic illness were positive for hepatitis C, which is low when compared to our study. In study by Arora et $\mathrm{al}^{6}{ }^{6}$ the prevalence of hepatitis $\mathrm{B}$ and $\mathrm{C}$ in patients of chronic liver disease was $28 \%$ and $13 \%$ respectively with $3 \%$ coinfection rate.

In the present study maximum prevalence of hepatitis $B$ infection is seen in 21 to 40 years' age group, which correlates with Singh et al $^{4}$ study who reported maximum prevalence of hepatitis B below 40 yrs. In the present study, maximum prevalence of hepatitis $C$ is also seen in 21 to 40 years' age group which is similar to Sarin SK et al ${ }^{7}$ study where the maximum prevalence was in this age group where the mean age of the patients was 35.9 yrs., whereas in Singh et $\mathrm{al}^{4}$ study the majority of the HCV patients were above 40 yrs. with mean age of 46.5 yrs. which is contrary to the results of our study.

In our study, the control group has shown a slightly higher percent of hepatitis B infection (10\%) when compared to normal prevalence in India. India comes in the intermediate prevalence range for hepatitis B with about $2 \%$ - $8 \%$ of the population being positive for hepatitis B. In studies conducted by Sinha et al ${ }^{8}$ and Gulia et al, ${ }^{9}$ the prevalence of hepatitis B in healthy population was $2.47 \%$ and $2.48 \%$ respectively, whereas in Makaroo et al 10 studies the prevalence was $10.22 \%$. Hepatitis C prevalence in our healthy population was $3 \%$, which is similar to the Sinha et $\mathrm{al}^{8}$ study where the prevalence was $1.7 \%$.

Thus, the present study identifies hepatitis $\mathrm{B}$ and $\mathrm{C}$ infections as an important risk factor for the development of chronic liver disease. Early detection of these infections will help not only in the appropriate management of the patients, but also to take necessary precautions to prevent the spread of these infections in a susceptible population.

\section{CONCLUSION}

To conclude hepatitis B is the major causative agent for chronic liver disease in our hospital, which is closely followed by hepatitis C. But with the wide introduction of the vaccination against hepatitis $B$, the prevalence of the disease can be expected to come down drastically in the future. In such a scenario, hepatitis C infection will be gaining importance in this group of patients. With the early diagnosis and implementation of proper preventive measures like immunisation of the population at risk will further reduce the incidence of these infections.

\section{REFERENCES}

1. Devi KS, Singh NB, Mara J, et al. Seroprevalence of hepatitis B virus and hepatitis C virus among hepatic disorders and injecting drug users in Manipur-a preliminary report. Ind J Med Microbiol 2004;22(2): 136-7.

2. Vandana B, Madanlal, Shevil R, et al. Prevalence of hepatitis $C$ in North India" a three years study. Journal of Advance Researchers in Biological Sciences 2012; 4(2): 120-2.

3. Liu Z, Hou J. Hepatitis B virus (HBV) and hepatitis C virus (HCV) dual infection. Int J Med Sci 2006;3(2):57-62.

4. Singh V, Katyal R, Kochhar RK, et al. Study of hepatitis B and $\mathrm{C}$ viral markers in patients of chronic liver disease. Indian Journal of Medical Microbiology 2004;22(4): 269-70.

5. Chakravarti A, Verma V. Prevalence of hepatitis C and B viral markers in patients with chronic liver disease: a study from northern India. Indian Journal of Medical Microbiology 2005;23(4):273-4.

6. Arora U, Mann A. Prevalence of hepatitis B virus, hepatitis $C$ virus, and HIV in patients of chronic liver disease in Amritsar. JIACM 2007;8(1):29-31.

7. Sarin SK, Guptan RC, Banerjee K, et al. Low prevalence of hepatitis $\mathrm{C}$ viral infection in patients with non alcoholic chronic liver disease in India. JAPI 1996;44(4):243-5.

8. Sinha SK, Roychoudhary, Biswas P, et al. Prevalence of HIV, hepatitis B, hepatitis $C$ and syphilis in donor's blood: a study from eastern part of India. Open Journal of Hematology 2012;7:3-1.

9. Gulia S, Panda S, Sitaramam E, et al. Seroprevalence of hepatitis B virus infection among blood donars in local population. The Internet Journal of Pathology 2010; 12:1-6.

10. Makroo RN, Chowdhry M, Bhatia A, et al. Hepatitis B core antibody testing in Indian blood donors: a double-edged sword!. Asian J Transfus Sci 2012;6(1):10-3. 